\title{
ARTIFICIAL NEURAL NETWORK IN THE MODELLING OF THE EFFECT OF CHROMIUM DOPANTS ON THE MECHANICAL PROPERTIES OF AL-4\% CU ALLOY
}

\author{
EYERE EMAGBETERE ${ }^{* 1}$, OGHENEKOWHO PETER ARUOTURE ${ }^{1}$, FESTUS \\ IFEANYI ASHIEDU ${ }^{1}$ \\ ${ }^{I}$ Department of Mechanical Engineering, Federal University of Petroleum Resources, \\ P.M.B 1221, Effurun, Nigeria
}

\begin{abstract}
Artificial Neural Network (ANN) was used to model the effect of Chromium dopants on the mechanical properties duralumin $(\mathrm{Al}-4 \% \mathrm{Cu})$. The results showed that the hardness, yield strength, and ultimate tensile strength increased, while the energy absorbed and percentage elongation decreased, with increasing \%wt of Chromium dopants. Simulation results of ANN show strong agreement with experimental values, having satisfactory Rvalues of Mean Square Error. ANN can suitably be used to predict the mechanical properties of $\mathrm{Al}-4 \% \mathrm{Cu}$ doped with Chromium.
\end{abstract}

Keywords: Aluminium composite, chromium dopants, tensile strength, hardness, percentage elongation, sand casting

\section{INTRODUCTION}

Aluminium based Metal Matrix Composites (AMMC) are widely used in structural applications due to their high strength-weight ratio. Their properties are modified suitably to meet up with the high demand for advanced materials in the aerospace and automobile industries [1,2]. The $\mathrm{Al}$ 6xxx series, in particular, is one of the $\mathrm{Al}$ composites commonly used in the development of aircraft components [3]. They have high corrosion resistance and good strength to weight ratio [4]. There are several ways of producing AMMC [2]. However, the sand casting method is the least expensive [5-7].

Some substances ranging from ceramics, agro-waste to mineral elements have been used as dopants to alter the properties of AMMC. Some ceramic materials such as $\mathrm{SiC}[8,9], \mathrm{Al}_{2} \mathrm{O}_{3}$ and $\mathrm{SiO}$ [10, 11], and $\mathrm{MoS}_{2}$ powders [12] have been reportedly used to improve the hardness and wear resistance of AMMC. The densities of ceramic materials are higher than AMMC, thus would negatively affect the over-all strength-weight ratio. Also, the nonuniform distribution of particles has been reported for certain ceramics dopants [13]. Agro-waste such as fly ash has also been used to improve the properties of AMMC $[5,14,15]$. Some of these materials are combined to form hybrid AMMC. A review of such hybrid AMMC is given by [16]. For now, hybrid composites are faced with porosity issue and uneven distribution of dopants [17, 18]. Several mineral elements have also been used to alter the properties of AMMC. A review of the effect of commonly applied major and minor elements used as dopants on AMMC is given by [19]. The effect of graphite on the microstructural and mechanical properties of Al6082 was reported in [20].

In recent time, Artificial Neural Network (ANN) has gained wide acceptance in the modelling of composite materials. Unlike conventional regression models, ANN can be used to model the nonlinear characteristics of metal composites [21]. Application of ANN as a modelling or data fitting tool can be likened to the brain's ability to acquire knowledge from experience. ANN usually has an input layer, an output layer and one or more hidden

\footnotetext{
* Corresponding author, email: emagbetere.eyere@fupre.edu.ng

(C) 2019 Alma Mater Publishing House
} 
layers, all of which constitutes the network structure or architecture. There are two types of network architecture, namely, feedforward system and back propagation. The backpropagation architecture has its output route back to its previous layer while the feedforward network has no diverted cycle. The backpropagation network is mostly utilised for modelling composite behaviours [22, 23]. Training is a significant step after the ANN structure is developed.

ANN model is usually trained to be able to mimic the given data. Various types of algorithms developed over the years for training ANN models are discussed in the literature [24]. For the back propagation networks, the Levenberg-Marquardt algorithm has been shown to give the best predictions [23]. The effectiveness of the ANN models is usually accessed using R-values and Mean Square Errors. Most of the ANN models for predicting composites behaviour typically have a high level of accuracy, showing minimal error and R-values as high as 0.9 [25].

One common area of application of ANN is the modelling of experimental data for forecasting. The computational time as affected by different algorithms, associated errors, and coding techniques have been reported for modelling sheet metals with ANN [22]. ANN can predict the complex behaviour of AMMC within a short time, using relatively small data set [2]. Some ANN AMMC models have been developed over the years. For most of the ANN AMMC models, the input variables were the percentage dopants and other factors which can affect the properties of the composite material. In the work of Varo et al. (2013) reinforcement ratio and milling time were used to predict density, hardness and tensile strength of Al2024-B4C composites produced by powder metallurgy. Also, the prediction of corrosion and hardness using percentage dopants, sintering time and temperature as input variables have been reported [26]. The percentage constituent elements of Al composites have been used as inputs to predict different outputs such as hardness [27], wear resistance [28], wear loss and surface roughness [29], and hardness, density and porosity [26]. Some models for predicting different mechanical properties based on the combination of processing parameters and percentage combination has been developed [30]. Squeeze pressure, die preheat temperature and melt temperature has also been used to predict ultimate tensile strength, hardness and yield strength [31].

Due to a large number of mechanical properties of $\mathrm{Al}-4 \% \mathrm{Cu}$ that is affected by the percentage dopants, it can be difficult to predict accurately using conventional methods. The ANN models that have been reported for AMMC have just three or less of outputs; thus their application for all mechanical properties as affected by percentage dopants is minimal. Furthermore, information on the effectiveness of this technique in the modelling of Al-4\% $\mathrm{Cu}$ composites doped with chromium is sparse, whereas it could be a useful predictive tool. This study is aimed at: firstly, to develop an ANN model for Al-4 \% Cu composites that can predict mechanical properties as affected by the percentage of Chromium dopant; and then to assess its performance as a predictive tool for this purpose.

\section{EXPERIMENTAL SETUP}

\subsection{Experimental details}

The starting materials were: Aluminium 6063 ingots obtain from the Nigeria Aluminum Extrusion Company, Nigeria; high purity Copper rod obtained from the Chemical market, Onitsha, Nigeria and Chromium metal powder obtained from Ogbete market, Enugu, Nigeria.

A $15.294 \mathrm{Kg}$ charge mass of the constituting elements was used for the experiments. The charge had $96 \%$ (14.4 $\mathrm{Kg})$ Aluminium and $4 \%(0.606 \mathrm{Kg})$ of Copper, and an additional $2 \%(288 \mathrm{~g})$ and $1 \%(0.006 \mathrm{~g})$ of Aluminium and Cupper respectively, to cater for oxidation losses.

To prepare a $15 \mathrm{Kg}$ charge mass of duralumin (Al-4\% Cu), $0.606 \mathrm{Kg}(4 \%)$ of as-received Copper plus an extra $0.006 \mathrm{~g}(1 \%)$ to cater for oxidation losses were charged into a 100kg capacity bailout graphite crucible furnace and then heated till it was completely melted. Afterwards, $14.4 \mathrm{Kg}(96 \%)$ of as-received Aluminium 6063 ingots plus an extra $0.288 \mathrm{~g}(2 \%)$ to cater for oxidation losses was charged into the furnace. The Aluminium and Copper melt was then stirred for about two minutes to achieve a homogenous mix. The molten $\mathrm{Al}-4 \% \mathrm{Cu}$ homogenous mix was then poured out on a prepared sand bed and allowed to solidify at room temperature.

Chromium powder in steps of $0.25 \mathrm{wt} \%$ from $0.25 \mathrm{wt} \%$ to $5 \mathrm{wt} \%$ was added to the appropriate amount of Al-4 $\% \mathrm{Cu}$ to prepare doped samples. The mixtures were melted in a mild steel crucible pot placed inside the furnace 
and thoroughly stirred for about two minutes to obtain a homogenous mix. The homogenous mix obtained was poured into a cylindrically shaped mould.

The prepared samples were then machined to produce test pieces for the different mechanical tests to be carried out. The prepared samples were viewed on a Digital Reflected light Metallurgical Microscope at X400 magnification. The Brinnel hardness test was carried out on test pieces (10 mm diameter by $15 \mathrm{~mm}$ length) of the different samples following ASTM E10 standard using a Gunt Brinell hardness tester. The Brinnel hardness number (BHN) was calculated using equation 1:

$$
B H N=\frac{p}{\frac{\pi}{2} D \cdot\left(D-\sqrt{D^{2}-d^{2}}\right)}
$$

Where $p$ is applied load in $\mathrm{kg}$; D - diameter of indenter in $\mathrm{mm}$; $\mathrm{d}$ - impressed diameter in $\mathrm{mm}$.

The tensile test was carried out on test pieces using the Testrometric universal testing machine model M500-25KN following the ASTM E8/E8M Standard. The dimensions of the cutout piece were: $32 \mathrm{~mm}$ length of reduced section, $25 \mathrm{~mm}$ gauge length, $6.35 \mathrm{~mm}$ reduced section diameter and $8 \mathrm{~mm}$ fillet radius. The ultimate tensile strength, yield strength and percentage elongation were recorded.

Impact test was carried out on test pieces using a modified form of the ASTM E23 following standard procedure. Cylindrical test pieces of $8 \mathrm{~mm}$ diameter and $40 \mathrm{~mm}$ length was used instead of a square bar. The test was conducted at room temperature $\left(27^{\circ} \mathrm{C}\right)$ using a Birmingham impact testing machine, and striking velocity was 10 $\mathrm{rad} / \mathrm{s}$.

\subsection{Artificial Neural Network modelling}

Artificial Neural Network (ANN) was implemented in MATLAB. The percentage of chromium dopant was used as the model input while the yield strength, ultimate tensile strength, percentage elongation, hardness and absorbed energy were used as outputs. The experimental data was split into $70 \%$ (11 samples), $15 \%$ (3 samples) and $15 \%$ (3 samples) for training, validation and test, respectively, of the ANN model. The model was trained with the Levenberg-Marquardt algorithm. The performance of the model was accessed using Root Mean Square Error (RMSE) and Mean Square Error (MSE) calculated with equations (2) and (3) respectively. The structure of the ANN is shown in Figure 1.

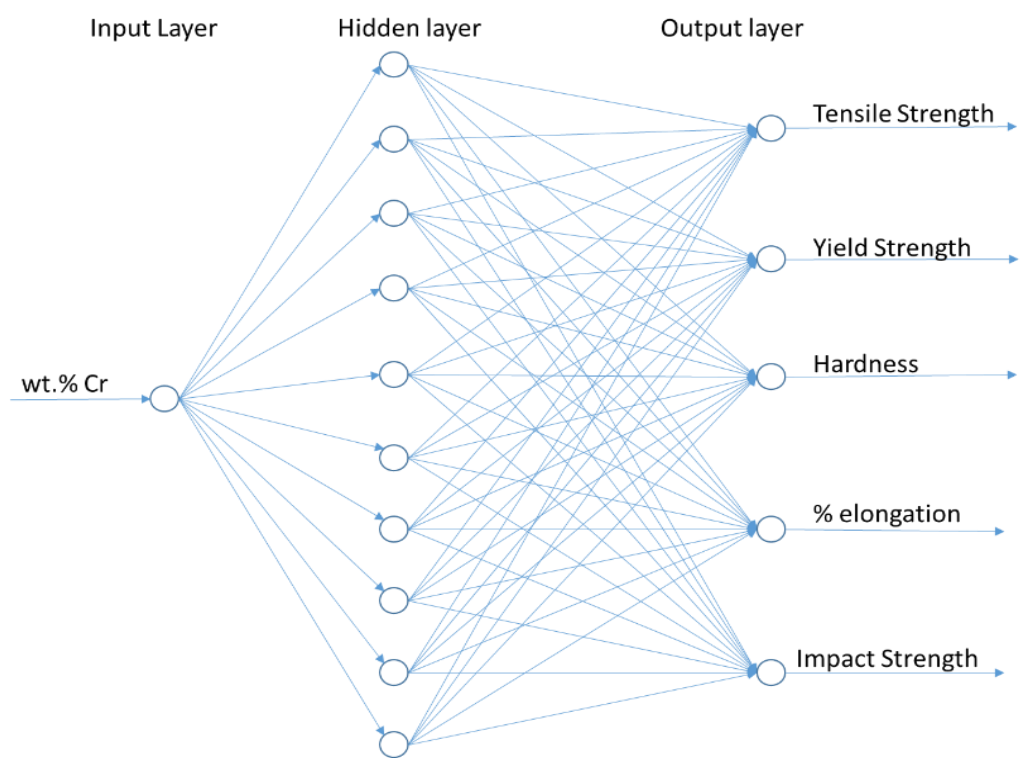

Fig. 1. The ANN Model Architecture.

$$
R M S E=\sqrt{\frac{1}{N_{T}} \sum_{k=1}^{N_{T}}\left(A V_{k}-P V_{k}\right)^{2}}
$$




$$
M S E=\frac{1}{N_{T}}\left(\sum_{k=1}^{N_{T}}\left[\left\lfloor\frac{\left(A V_{k}-P V_{k}\right)}{A V_{k}} \mid\right]\right)\right.
$$

\section{RESULTS AND DISCUSSION}

\subsection{Effect of dopants on the Microstructure}

The micrographs of selected samples are shown in Figure 2 to 7 . Grain boundaries were found to increase with the $\%$ wt $\mathrm{Cr}$ added. Grain boundaries serve as a blockade to dislocation movement. Thus increasing number of grain boundaries will likely affect the ductility negatively while hardness may be increased.

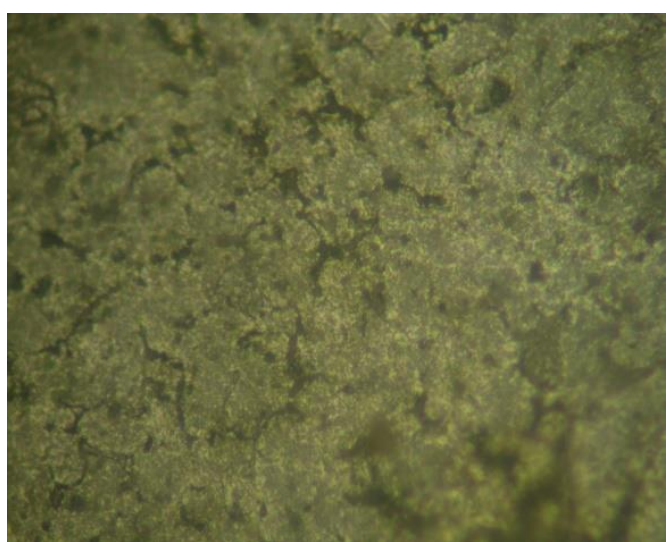

Fig. 2. Micrograph of $\mathrm{Al}-4 \% \mathrm{Cu}(\mathrm{x} 400)$.

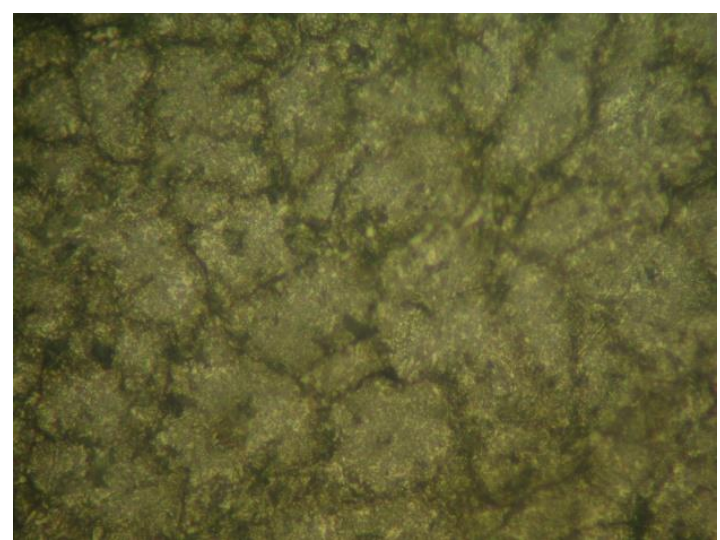

Fig. 4. Micrograph of Al-4\% Cu-2.0\% wt Cr (x400).

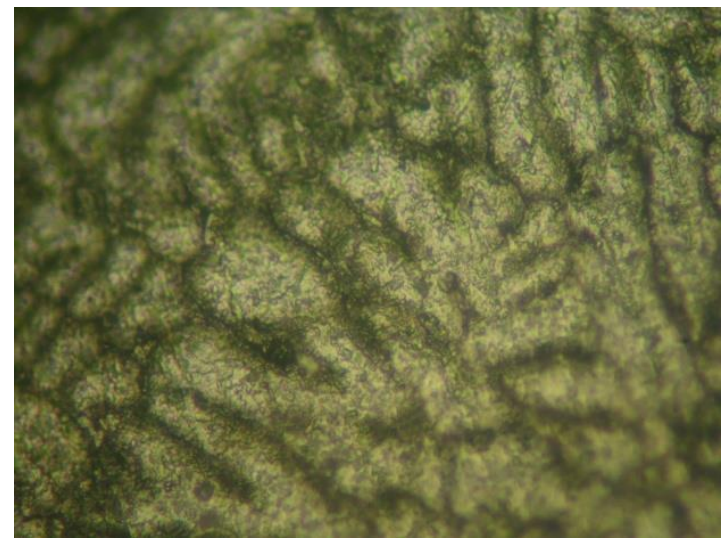

Fig. 6. Micrograph of Al-4 \% Cu-3.5 \% wt Cr (x400). Fig. 7. Micrograph of Al-4\% Cu-4.0 \% wt Cr (x400).

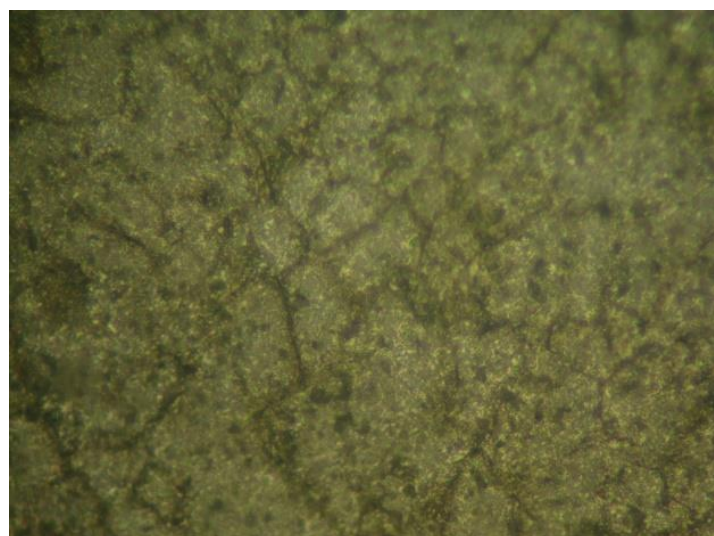

Fig. 3. Micrograph of Al-4 \% Cu-1.0 \%wt Cr (x 400).

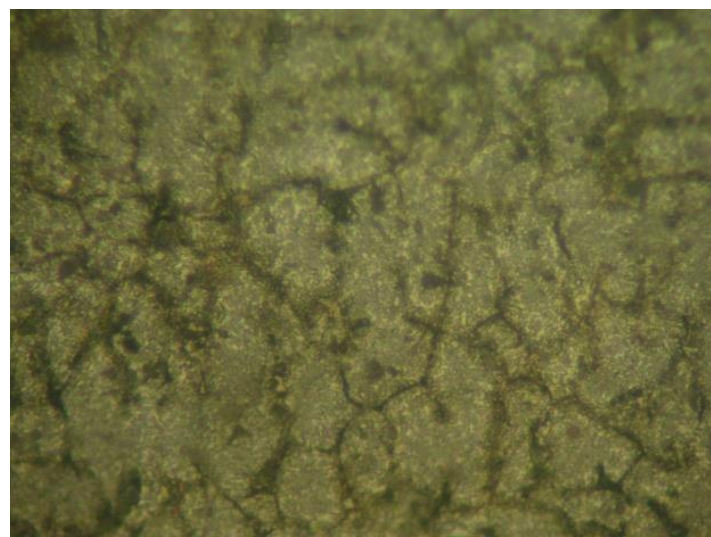

Fig. 5. Micrograph of Al-4 \% Cu-2.5\% wt Cr (x400).

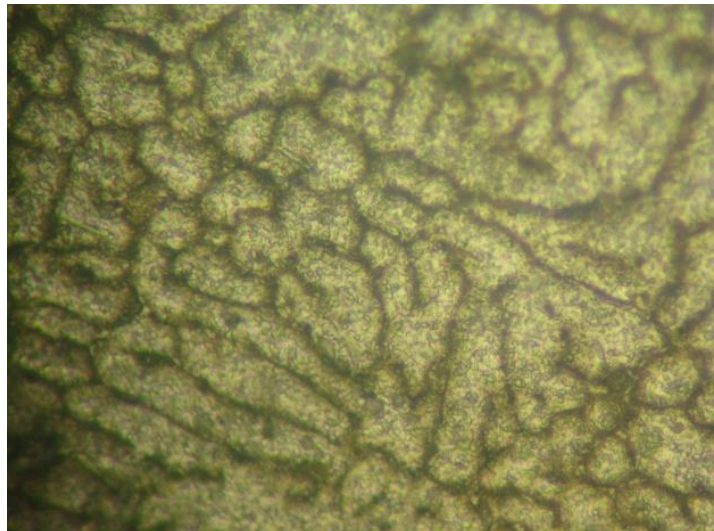




\subsection{Impact test}

Figure 8 shows the energy absorbed against the percentage weight of chromium. This was obtained via an Impact test which measures the energy that is absorbed by a material during fracture. The absorbed energy was found to decrease with an increasing percentage of $\mathrm{Cr}$. This implies that the material was becoming less ductile as the percentage of Chromium added increased.



Fig. 8. Impact test Plot (Percentage weight of Chromium versus Absorbed energy).

\subsection{Hardness Test}

The hardness of $\mathrm{Al}-4 \% \mathrm{Cu}$ plotted against percentage $\mathrm{Cr}$ dopants is shown in Figure 9. It can be seen that the hardness increased with increasing percentage $\mathrm{Cr}$ dopants. The increasing hardness can be attributed to the doping element aiding formation of more grain boundaries and occupying spaces in the grain boundaries thereby resisting grain boundary dislocations.

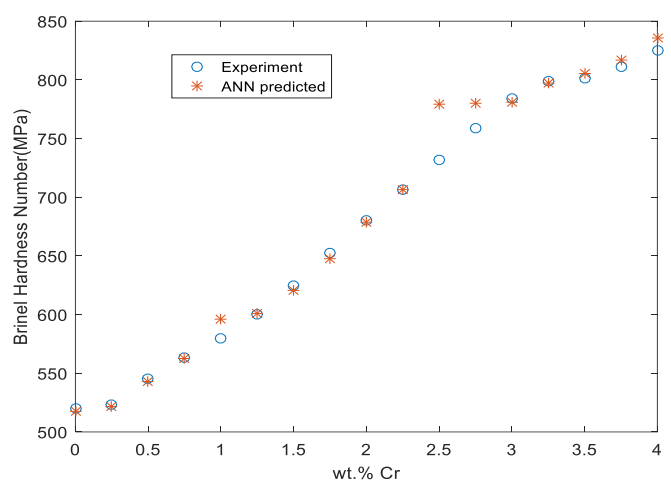

Fig. 9. The result of the hardness test.

\subsection{Tensile test}

The tensile test revealed the effect of the percentage dopants on the yield strength, ultimate tensile strength and percentage elongation of the material at yield. The percentage elongation versus \% $\% \mathrm{Cr}$ is shown in Figure 10. Values of \% elongation were found to decrease as the \% wt $\mathrm{Cr}$ increases. This is because the material was becoming increasingly harder but less ductile as the $\%$ wt $\mathrm{Cr}$ increased.

Figure 11 and 12 show the effect of $\%$ wt $\mathrm{Cr}$ dopant, on the yield strength and ultimate tensile strength respectively. The yield strength and ultimate tensile strength increase with \% wt of Cr dopants up to $2.5 \%$, beyond which the values of tensile strength were found to decrease with increasing $\% \mathrm{wt} \mathrm{Cr}$. This shows that the tensile (and yield) strength increased as \% wt $\mathrm{Cr}$ increased up to $2.5 \%$ and the material becomes progressively harder. As the \% wt Cr increased beyond $2.5 \%$, the material transited from a ductile to a brittle material and so the tensile (and yield) strength began to drop as the \% wt Cr increased even though the material's hardness continued to increase. 


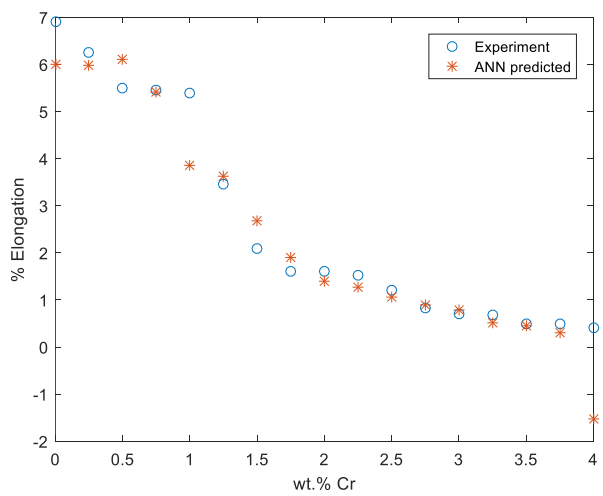

Fig. 10. The result of the tensile test, Percentage weight of Chromium versus percentage elongation during the uniaxial test.



Fig. 11. Tensile test result; Percentage weight of Chromium versus Yield strength.



Fig. 12. Tensile strength, Percentage weight of Chromium versus ultimate tensile strength.

\subsection{Result of ANN Modelling}

In this study, the developed ANN model was used to predict the ultimate tensile, yield strength, percentage elongation, hardness and absorbed energy (impact strength) as affected by $\% \mathrm{wt} \mathrm{Cr}$ dopants. The predicted values are shown in Figure 8 to 12.

Figure 13 shows the Mean Square Error (MSE) of the developed ANN model for different instances of iteration. The MSE rapidly dropped for the testing, validation and test data set. The validation and test data set had similar characteristics indicating that the values of MSE are reasonable. No significant overfitting had occurred at the $83^{\text {rd }}$ iteration, having minimum MSE of 101.45. At this point, best validation performance occurred.

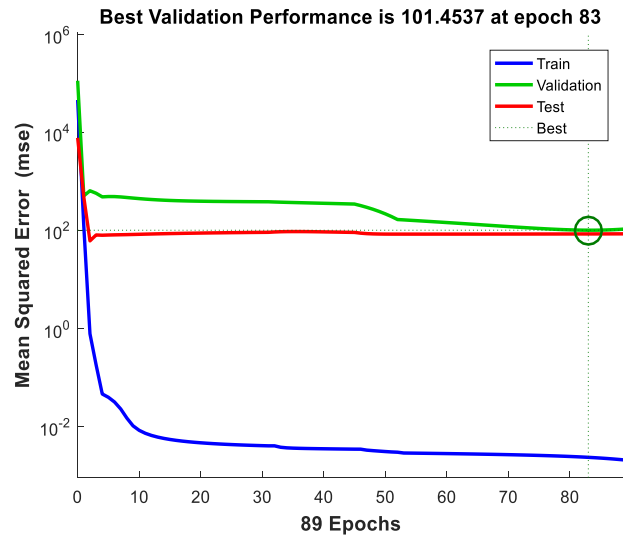

Fig. 13. Performance of the Network for the different training stages.



Fig. 14. Error histogram for the model. 
The error histogram for 20 bins is presented in Figure 14. The errors were obtained by finding the difference between targets (experimental values) and outputs (ANN model predicted values). The errors range from -27.58 to 24.8 in the different instances. Although some validation and test data had error values of -2.77 and 2.76 , respectively, most of the instances had a minimum error, being -0.01193 .

Figure 15 to 17 show the regression plots for the training, validation and testing data sets, respectively. It represents the network outputs with their corresponding targets. As observed, most of the data set fell along the 45-degree line where network outputs are equal to targets. The fit is reasonably good for all the data sets with R-values being $1,0.99$ and 0.99 for training, validation, and testing respectively. R-value of 1 for the training data set indicates that the ANN model perfectly mimics the data set used for its training. R-values being very close to 1 for validation and test data set indicate high accuracy of prediction using the ANN model.

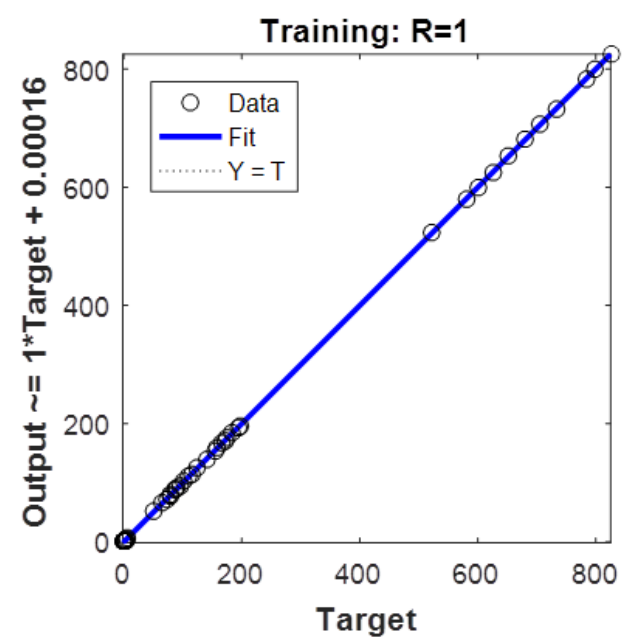

Fig. 15. Regression plot for the training data set.

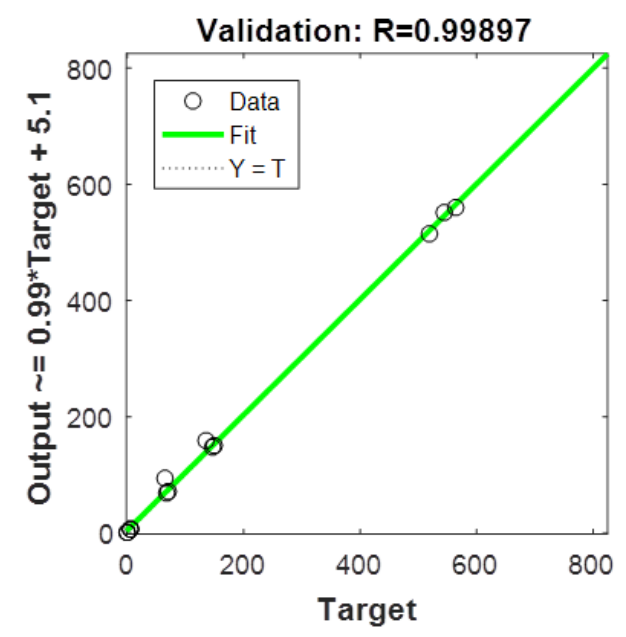

Fig. 16. Regression plot for the validation data set.

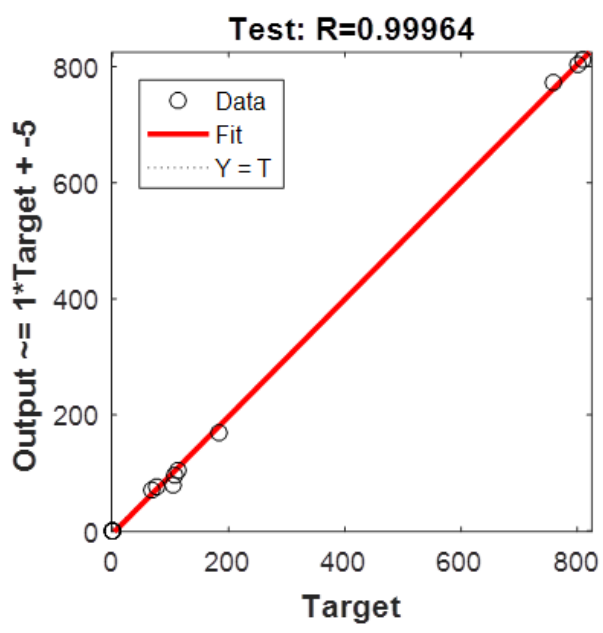

Fig. 17. Regression plot for the test data set.

\section{CONCLUSIONS}

Samples of Al-4\% Cu composite doped with Cr varied from 0 to 4 wt \% in steps of $0.25 \%$ reinforcement size was successfully produced via the sand casting method. The ultimate tensile strength, yield strength, percentage elongation, hardness and impact strength were determined following ASTM standard. ANN was successfully applied to model the effect of wt \% of $\mathrm{Cr}$ reinforcement on the ultimate tensile strength, yield strength, percentage elongation, hardness and impact strength of $\mathrm{Al}-4 \% \mathrm{Cu}$ composites in this study. The following conclusions were thus drawn:

1. Chromium can be used as dopants to improve the mechanical properties of $\mathrm{Al}-4 \% \mathrm{Cu}$ alloy 
2. Chromium dopants can be uniformly dispersed on $\mathrm{Al}-4 \% \mathrm{Cu}$ as observed via micrographs.

3. The increase in hardness of the doped samples for a particular dopant is proportional to the percentage weight composition of the dopant for the range covered in the study.

4. Doping Al-4 \% Cu alloy with $\mathrm{Cr}$ resulted in the loss of ductility of the alloy.

ANN effectively modelled the mechanical characteristics of AL-4 \% Cu composite. Therefore ANN can be used to estimate the mechanical properties of AL- $4 \% \mathrm{Cu}$ composites doped with $\mathrm{Cr}$ satisfactorily, thereby reducing the testing time and cost of experiments.

\section{REFERENCES}

[1] Tang, F., Anderson, I.E., Gnaupel-Herold, T., Prask, H., Pure Al matrix composites produced by vacuum hot pressing : tensile properties and strengthening mechanisms, Materials Science and Engineering. A, vol. 383, 2004, p. 362-373.

[2] Varol, T., Canakci, A., Ozsahin, S., Composites : part B Artificial neural network modeling to effect of reinforcement properties on the physical and mechanical properties of Al2024 - B 4 C composites produced by powder metallurgy, Composites Part B, vol. 54, 2013, p. 224-233.

[3] Yashpal, C., Jawalkar, S., Kant, S., A review on use of aluminium alloys in aircraft components, i-manager's Journal on Material Science, vol. 3, no. 3, 2015, p. 33-38.

[4] Dursun, T. Soutis, C., Recent developments in advanced aircraft aluminium alloys, Materials and Design, vol. 56,2014 , p. $862-871$.

[5] Lancaster, L., Lung, M.H., Sujan, D., Ash, A.C.S., Utilization of agro-industrial waste in metal matrix composites : towards sustainability," International Journal of Environmental and Ecological Engineering, vol. 7, no. 1, 2013, p. 35-43.

[6] Surappa, M.K., Aluminium matrix composites: challenges and opportunities, Sadhana, vol. 28, no. 1-2, 2003, p. 319-334.

[7] Sharma, P., Khanduja, D., Sharma, S., Tribological and mechanical behaviour of particulate aluminium matrix composites, Journal of Reinforced Plastics and Composite, vol. 33, no. 23, 2014, p. 2192-2202.

[8] Anggara, B.S., Handoko, E., Soegijono, B., Mechanical properties of Al-Cu Alloy-SiC composites, 3rd International Conference on Theoretical and Applied Physics, vol. 109, no. 2014, 2013, p. 1-4.

[9] Anggara, B.S., Soegijono, B., Mechanical properties of metal $\mathrm{Al} / \mathrm{SiC}$ and $\mathrm{AlCu} / \mathrm{SiC}$ metal matrix composites (MMCs), Conference on Science and Engineering for Instrumentation, Environment and Renewable Energy, vol. 2016, 2015, p. 1-5.

[10] Bodukuri, A.K., Eswaraiah, K., Rajendar, K., Sampath, V., Fabrication of Al-SiC-B4C metal matrix composite by powder metallurgy technique and evaluating mechanical properties, Perspectives in Science, vol. 8, 2016, p. 428-431.

[11] Altinkok, N., Use of artificial neural network for prediction of mechanical properties $\mathrm{Al}-\mathrm{Si} 10 \mathrm{Mg}$ alloy composites prepared by using stir casting process, Journal of Composite Materials, vol. 40, no. 9, 2006, p. 779795.

[12] Rebba, B., Ramanaiah, N., Evaluation of mechanical properties of aluminium alloy (Al-2024) reinforced with molybdenum disulphide (MOS 2) metal matrix composites, Procedia Materials Science, vol. 6, no. ICMP, 2014, p. 1161-1169.

[13] Rahman, M.H., Al-Rashed, H.M.M., Characterization of silicon carbide reinforced aluminium matrix composites, Procedia Engineering, vol. 90, no. ICME 2013, 2014, p. 103-109.

[14] Kanayo, K., Moyosore, T., Apata, P., Corrosion and wear behaviour of Al-Mg-Si alloy matrix hybrid composites reinforced with rice husk ash and silicon carbide, Journals of Materials Research and Technology, vol. 3 , no. 1,2014 , p. 9-16.

[15] Alidokht, S.A., Abdollah-Zadeh, A., Soleymani, S., Assadi, H., Microstructure and tribological performance of an aluminium alloy based hybrid composite produced by friction stir processing, Materials and Design., vol. 32, no. 5, 2011, p. 2727-2733.

[16] Singh, J., Chauhan, A., Characterization of hybrid aluminum matrix composites for advanced applications a review, Journals of Materials Research and Technology, vol. 5, no. 2, 2016, p. 159-169.

[17] Alaneme, K.K., Aluko, A.O., Production and age-hardening behaviour of borax premixed SiC reinforced AlMg-Si alloy composites developed by double stir-casting technique, West Indian Journal Engineering, vol. 34, no. 1/2, 2012, p. 80-85.

[18] Siva, D., Shoba, C., Ramanaiah, N., Investigations on mechanical properties of aluminum hybrid composites, Journals of Materials Research and Technology, vol. 70, 2014, p. 1-7. 
[19] Rana, R.S., Purohit, R., Das, S., Reviews on the influences of alloying elements on the microstructure and mechanical properties of aluminum alloys and aluminum alloy composites, International Journal of Scientific and Research Publications, vol. 2, no. 6, 2012, p. 1-7, 2012.

[20] Sharma, P., Sharma, S., Khanduja, D., A study on microstructure of aluminium matrix composites, Journal of Asian Ceramic Societies, vol. 3, no. 3, 2015, p. 240-244.

[21] Emadi, D., Mahfoud, M., Comparison of artificial neural network and multiple regression analysis techniques in predicting the mechanical properties of A356 Alloy, Procedia Engineering, vol. 10, 2011, p. 589-594.

[22] Kashid, S., Kumar, S., Applications of artificial neural network to sheet metal work - a review, American Journal of Intelligent Systems, vol. 2, no. 7, 2013, p. 168-176.

[23] Koker, R., Neural network-based prediction of mechanical properties of particulate reinforced metal matrix composites using various training algorithms, Materials and Design, vol. 28, 2007, p. 616-627, 2007.

[24] Sumathi, S., Surekha, P., Computational intelligence paradigms theory and applications using MATLAB. Boca Raton: CRC Press, 2010.

[25] Offiong, A., Ihom, A.P., Neural networks in materials science and engineering: a review of salient issues, European Journal of Engineering and Technology, vol. 3, no. 7, 2015, p. 40-54.

[26] Hassan, A.M., Alrashdan, A., Hayajneh, M.T., Mayyas, A.T., Prediction of density , porosity and hardness in aluminum - copper-based composite materials using artificial neural network, Journals of Materials Processing Technology vol. 9, 2008, p. 894-899.

[27] Zahran, B.M., Using neural networks to predict the hardness of aluminum alloys, Engineering, Technology and Applied Science Research, vol. 5, no. 1, 2015, p. 757-759.

[28] Hayajneh, M., Hassan, A.M., Alrashdan, A., Mayyas, A.T., Prediction of tribological behavior of aluminum - copper based composite using artificial neural network, Journal of Alloys and Compounds, vol. 470, 2009, p. 584-588.

[29] Durmuş, H.K., Özkaya, E., Meriç, C., The use of neural networks for the prediction of wear loss and surface roughness of AA 6351 aluminium alloy, Materials. Designs, vol. 27, no. 2, 2006, p. 156-159, 2006.

[30] Thankachan, T., Prakash, K.S., David, C., Artificial neural network to predict the degraded mechanical properties of metallic materials due to the presence of hydrogen, International Journal of Hydrogen Energy, vol. 42, no. 47, 2017, p. 28612-28621.

[31] Soundararajan, R., Ramesh, A., Sivasankaran, S., Sathishkumar, A., Modeling and analysis of mechanical properties of aluminium alloy (A413) processed through squeeze casting route using artificial neural network model and statistical technique, Advances in Materials Science and Engineering, vol. 2015, 2015, p. 1-16. 